\title{
CONTRAPONTO \\ A escola e a formação da cldadania ou para além de uma concepção reprodutivista
}

\author{
Sórglo António da Silva Lelte *
}

O interessante artigo da psicó. loga Cecilia Maria B. Coimbra, "As funcỏes da instituiçảo escolar: análises e reflexòes", publicado nesta ediçāo, sugere uma série de questôes bastante polêmicas, a respeito das diferentes concepçōes sobre o papel da Escola no desenvolvimento da sociedade brasileira. No sentido de colaborar para o debate, apresento algumas reflexóes que julgo oportunas.

Para se discutir a questảo pro. posta, gostaria de iniciar colocando a pergunta central: a Escola é uma instituiçào fundamental para a for. maçào da cidadania?

Obviamente, estamos entendendo cidadania no seu sentido mais amplo possivel, ou seja, o exercicio pleno dos direitos e deve. res de cidadào numa sociedade de. mocrätica, incluindo a participaçào efetiva em todo o processo social como sujeito histórico, de forma critica e consciente. Alèm disso, a questảo colocada pretende enfocar principalmente a Escola pública atual, com os problemas que todos jâ conhecem.

Esta questão nos leva a discu. tir sobre o papel da Escola. Isto porque entendo que a atuaçảo dos profissionais da Educaçào depende muito da concepçào que se tem sobre o papel da Escola em nossa sociedade. Por exemplo: a concepcaá de que a Escola tem pouca participação no processo de transformaçōes sociais, implicará um engajamento politico-social onde a açào transformadora nāo priorizará o espaco intra-escolar. Por outro lado,

(*) Doutor em Psicologia. Professor do Departamento de Psicologia Educactonal da faculda de de Educaçá-UNICAMP.

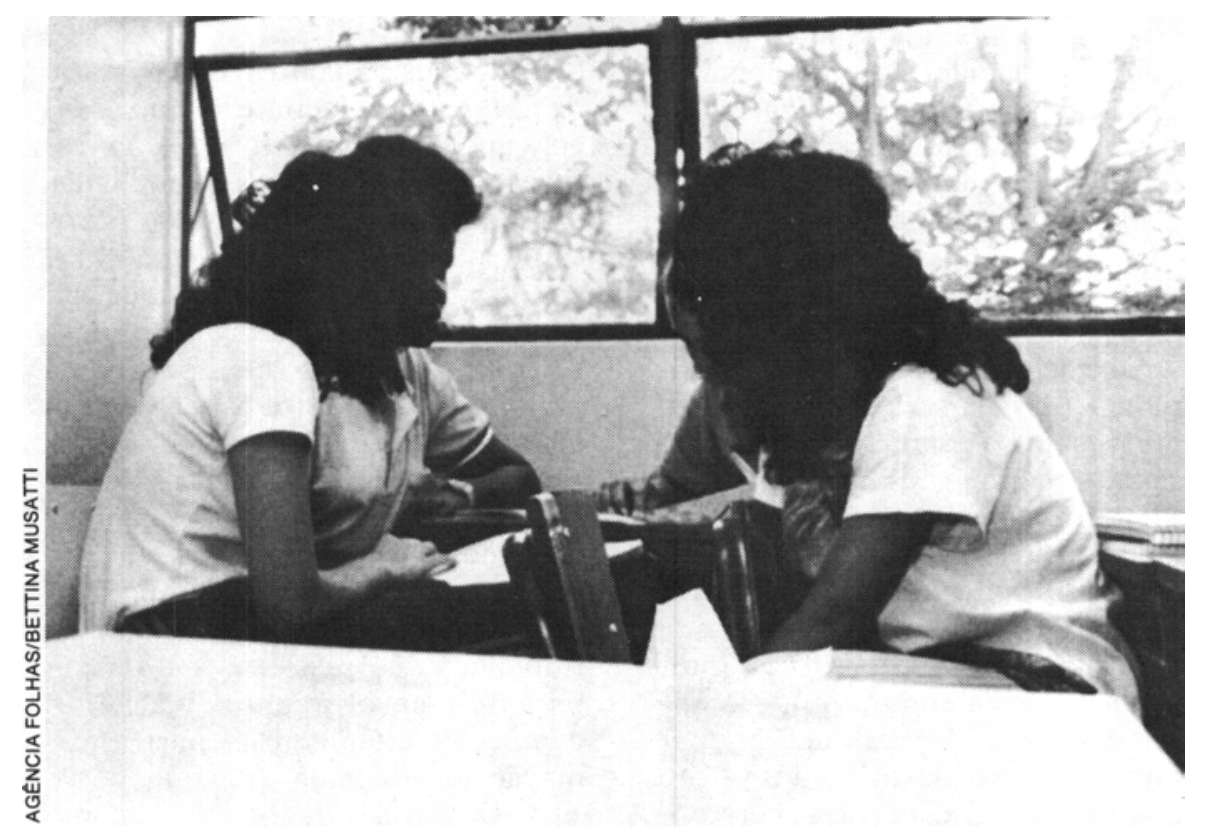

entendendo-se que a Escola tem um papel fundamental no desenvolvimento do processo social mais amplo, o espaço intra-escolar será visto como um dos locus prioritários para a açào de grupos e profissionais comprometidos com idéias transformadoras ou revolucionárias.

Ao analisarmos a literatura, tentando indentificar como as várias correntes teóricas ou diferentes autores interpretam o papel da Es. cola nos diversos momentos históricos, vamos perceber que a concepçào de Escola caracteriza-se pela pluralidade ideológica e, mesmo a. nalisando-se uma determinada con. cepçăo, percebe-se que ela nunca $\dot{e}$ estática, sofrendo constantes trans. formaçóes, em função de dados de pesquisas e aprimoramento de aná. lise que ajudam o desenvolvimento de uma determinada teoria. Uma excelente amostra dessa pluralidade é descrita no capítulo 1 do livro. Escola, Estado e Sociedoude, de Bár. bara Freitag.

Assim, dentre essas varias teorias ou concepcoies sobre o papel da Escola, temos, por exemplo, a visāo idealista-liberal, em que a Escola é vista como instrumento de democa. tizaçào e integraçào, na medida em que, sendo de boa qualdiade, poderia garantir uma condiçào de igualdade de oportunidades para todos os individuos. Tal concepçào mostrou-se inviável, pelo menos até ho. je, uma vez que nào se pode falar em igualdade de oportunidades sem que exista igualdade de condiçóes, o que nảo caracteriza o nosso sistema capitalista. A própria autora do artigo citado, Cecilia Maria Coimbra, aponta alguns mitos que devem ser superados visando a uma melhor compreensão da Escola em nossa sociedade. 
Num outro extremo, eneontramos umá visio um tanto quanto anárquica, tirando dá atual Escola' qualquer possibilidade de colaborar no processo de transformaçāo social. Como exemplo, cita-sc Ivan IIlich, em sua obra Sociedade sem Escolas.

As teorias, porém, que mais nos interessam agora são as concepçöes crítico-reprodutivistas, que têm dominado o cenário acadèmico nos últimos anos, representadas por autores como Establet, Baudelot, Passeron e Bourdieu, destacando-se ainda Althusser e Gramsci, que interpretam a Escola como aparelho ideológico do Estado, através do qual os setores dominantes tentam exercer seu poder hegemônico. Neste sentido, o sistema educacional é visto como um instrumento de transmissāo ideológica, ou seja, da ideologia dominante, subjacente ao capitalismo, que tem por funçāo levar os cidadàos a aceitarem passivamente as formas de produçāo, de organizaçào e de reproduçào do sistema. A Escola seria um dos instru. mentos que o Estado utiliza para essa tarefa.

Grosso modo, poderíamos identificar dois grandes grupos nes. se grande conjunto de teorias critico-reprodutivistas. Um deles, mais fiel as concepçoes marxistas, interpreta a Escola como um mero aparelho do Estido, submetida, portanto, ao controle direto dos setores dominantes. Nesta perspectiva, o sistema educacional transformar-se-á somente a partir do momento $\mathrm{em}$ cue as forças progressistas $\mathrm{e}$ / ou revolucionarias assumirem o controle efetivo do Estado. Como conseqüència desta concepçào, a possivel açāo politico-transformadora intra-escolar nào é priorizada, embora sua importância nào seja totalmenté negada.

Num segundo grupo, encontram-se as concepçòes modernamente influenciadas pelas idéias de Gramsci, que visualiza, de um lado, a existência da Sociedade Policica, representada pelo Estado e todos os seus instrumentos legais, persuasivos e repressivos, e de outro, a Sociedade Civil, caracterizada pela pluralidade ideológica, formada pelo conjunto de instituiçóes eivis como a lgreja, os partidos, os meios de comunicaçào, os sindicatos, as entidades, ete..., e a Fscola. Nesta concepceào, a Sociedade Política, atra- vés de açáo direta ou indireta dos grupos dominantes, tenta exercer o controle ideológico da Sociedade Civil, buscando o máximo de influência sobre suas instituiçōes. Porém, a consecução dessa tarefa dependerá da existência de contra-ideologias, antepondo-se à dominante, através da açāo organizada de setores sociais, atuando dentro dessas instituiçòes. Assim, o confronto ideológico, na visảo gramsciana, dar-se-á efetivamente na Sociedade Civil. Como consequência, a açào de gru. pos progressistas e ou de revolucionários nas institujẹóes civis, como a Escola, passa a ser fundamental para o processo das transformações sociais.

A questăo central que gostaria de apresentar e debater é que essas concepçōes reprodutivas estāo começando a ser revistas e ampliadas em funcào principalmente de novos estudos e pesquisas que estào ajudando a perceber de forma mais clara o papel da Escola, principalmente para os setores mais pobres da populaçào. Tais estudos, se por um lado nào negam o papel ideologizante da Escola, têm demonstrado, por outro lado, que a Escola tem fun. ços muito importantes para as populaçóes marginalizadas, representando talvez uma das poucas oportunidades que esses setores teriam para o desenvolvimento de algumas condiçoes fundamentais para a formaçào da cidadania.

Gostaria de tomar como exemplo desses novos trabalhos, a pesquisa realizada por Bárbara Freitag, publicada no seu livro Sociedade e Consciència-Um Estudo Piagetiano na Favela e na Escola. Essa autora pesquisou as relaçōes entre a escolarizaçāo e o desenvolvimento das estruturas lógica, lingüistica e moral, tomando como referencial a teoria de Piaget. Em seu procedimento, que nào cabe aqui detalhar, avaliou o desenvolvimento dessas três estruturas, em crianças e jovens, com e sem escolarizaçào (oito anos do ensino de primeiro grau), selecionando sujeitos de três niveis sociais (classes $A, B$ e $C$ ), em diferentes idades.

Dentre os vários resultados observados, os que nos interessam sào os seguintes: a) a escolarizaçào regular (oito anos) favorece plenamente $o$ atingimento dos niveis mais altos nas escalas psicogenéticas de linguagem, moralidade e pensamen- to lógico; b) os jovens sem escolari. dade, comparados com os seus pa. res no final da oitava série, demonstraram defasagens de 6 a 8 anos, nas três classes sociais; c) os dados indicam que oito anos de escolarizacào apagam as diferenças de desempenho cognitivo, moral e lingüistico, observadas no inicio da escolarizaçào, certamente devido às diferenças de origem sócio-econòmica. $\mathrm{Ou}$ seja, a distribuiçào dos alunos no fi. nal da oitava série é homogênea, in. dependente da classe social a que pertencem.

Um dado interessante, é que nào há correlaçāo entre as notas es. colares e os niveis de competência, isto é, o fato dos alunos demostra. rem desenvolvimento nessas estruturas nāo implica que obtenham notas melhores, o que sugere que os currículos escolares nāo estāo ađaptados aos diferentes niveis de desenvolvimento ou yue existem outros fatores intra-escolares que interferem nesse processo.

Diante desses resultados, a autora conclui que a Escola tem um efeito democratizante sobre $o$ desenvolvimento psicogenético e sócio-lingüistico, independente dos conteúdos que desenvolve. As hipóteses que a autora apresenta tentam explicar tal efeito devido provavelmente às relaçóes sociais proporcionadas pela Escola, ou seja, as re. laçòes informais que os jovens expe. rienciam dentro da Escola, prineipalmente com os seus pares, seriam de fundamental importância para o desenvolvimento daquelas estruturas avaliadas.

Uma outra conclusāo, esta mais relacionada com o nosso tema, é que tais resultados levam necessa. riamente à revisão das concepçóes reprodutivas sobre a Escola: esta, apesar de ser um mecanismo de seletividade e de reproduçào de clas. ses sociais, é ao mesmo tempo uma instituiçāo social que funcionaria, ao nivel da formaçào das estruturas da consciência, como instrumento democratizante, como coloca Bár. bara Freitag.

Em outras palavras, significa que jovens com oito anos de escolarizaçào, apresentariam, independente da origem social, estruturas cognitivas que os possibilitariam assimilar e processar adequadamente as experiências externas.

A importancia disto para a nossa discussâo é óbvia: se assumir- 
mos que um dos objetivos da Escola deveria ser a formaça do comportamento critico, tal processo implica necessariamente o desenvolvimento das competências (estrutu. ras, na linguagem piagetiana) lógica, lingüística e moral; colocando a questão de forma inversa, nảo se desenvolve o comportamento critico, sem que essas estruturas, investigadas por Freitag, se desenvolvam.

Delineia-se, portanto, uma nova contradiçào: se por um lado a Escola tem transmitido uma ideologia hegemònica, por outro, a escolarizaçào tem desenvolvido o repertório básico que é fundamental para a formaçào da cidadania e talvez para a própria superaçào da condiçào de alienaçào. Obviamente, isto nāo significa que estamos defendendo a Escola tal qual se apresenta hoje, mas reconhecendo uma consequizência da escolarizaçāo que até entào nāo estava claramente colocada. Além disto, poder-se-ia imaginar que o papel da Escola poderia ser muito mais importante se estivesse planejada de acordo com as carac. teristicas e necessidades da populacào atendida; por exemplo, se os curriculos e programas escolares fossem planejados, respeitando-se $o$ repertório inicial da populaçāo e direcionados numa perspectiva de formaçào do comportamento critico, certamente teria um efeito de grande relevancia para a formaçāo da cidadania.

Os resultados de estudos como este permitem ainda outras conclusōes que levariam à revisào de certas concepçōes. Assim, se a origem social é um dos co-determinantes do desenvolvimento cognitivo, pode-se supor que tal processo nào é irreversivel, ou seja, a escolarizaçāo pode atuar, principalmente para as classes socialmente marginalizadas, como mecanismo de reequilibraçảo dessa defasagem.

Outra conclusào geral possivel è que o processo de reproduçào de classes, atribuido ao sistema escolar, ocorre concretamente pelas relaçòes de acesso / nāo acesso e permanência / não permanència. Daí, as conclusōes práticas que podem ser tiradas desses trabalhos: tào importante quanto a oferta de escolas, $\dot{e}$ a necessidade de se assegurar a permanència das erianças durante oito anos básicos, ou seja, nào basta que exista Escola, é preciso que os alunos possam freqüentá-la du- rante esse periodo. Tal necessidade é maior quanto mais pobre é a origem social do aluno, assumindo-se que o desenvolvimento global é, em grande parte, funçāo das condiçóes concretas de vida.

Diante desse quadro, resta questionar o seguinte: se a Escola tem um papel fundamental, mesmo na situaçào em que se encontra, por que nảo se tem garantido a perma. nência da maioria da populaçào durante o primeiro grau? $O$ que tem determinado o fracasso escolar (repetència e evasào) dos quase $80 \%$ das crianças que iniciam a primeira série e nào terminam o primeiro grau?

Muito já se escreveu e pesquisou sobre o assunto. Em outro trabalho sintese (Alfabetizaçăo e Fracasso Escolar-EDICON, 1988), tivemos a oportunidade de agrupar todos os fatores identificados pela pesquisa em dois grupos: os fatores extra e intra-escolares. No primeiro, situam-se as variáveis relacionadas com as condiçōes de vida, de. terminadas pela situaçào sócio-eco nômica, que constituem condiẹỏes concret as que impedem uma criança de frequientar regularmente uma Escola. No segundo grupo, há uma série de determinantes conhecidos, desde curriculos e programas inade. quados, até formaçào do professor, passando pelas condiçỏes internas como organizaçào e a burocratiza. cào escolar.

A questão que se coloca é: essa situaçào tem soluçào? É possivel alterar certas condiçôes e diminuir ou erradicar o fracasso escolar?

Entendo que a resposta a esta pergunta é afirmativa, mas qualquer proposta apresenta implicaçōes de ordem política. Assim, vejamos: o enfrentamento dos fatores extra.escolares depende da superaçào dos prineipais problemas sócio-econômicos que afetam nossa populaçào e isto dependerá fundamentalmente da capacidade de organizaçào dos setores sociais comprometidos com mudanças que atendam os interes ses da maioria da populaçāo, principalmente as parcelas historicamen. te marginalizadas.

Por outro lado, a superaçāo dos fatores intra-escolares também implica a questào política. Por exemplo: as decisóes que são tomadas nos diversos niveis das secretarias de Educacajo, dependem de quem ocupa os postos-chave, seja nos órgàos centrais, seja dentro da Escola. Dependem também do nivel de organizaçào dos educadores e do tipo de compromisso que eles assu. mam. Vejamos uma questào concreta: um dos grandes problemas que nossa Escola apresenta diz respeito à falta de continuidade curri. cular observada nas diversas diseiplinas, entre as diversas series. Este é um problema cuja soluçào implicará necessariamente a transforma. cào da estrutura e funcionamento concreto da Escola, pois implica a participaçào dos professores nos niveis de decisào com relaçâo às questóes dos conteúdos e das práticas escolares. Em outras palavras, implica a busca de novas formas de organizaçào dos educadores na Escola, o que exigirá uma divisāo de poder, atualmente centrado nas mảos do diretor. Sem que se tenha clareza desse processo, difieilmente conseguir-se-á resolver a questào da continuidade curricular, independente das propostas de funcionamento que os niveis centrais das secretarias de Educaçào venham sugerir. Da mesma forma, a análise de cada fator intra-escolar responsavel pelo fracasso escolar exigirá, para sua soluçāo, decisòes de cunho basicamente político-pedagógico, discutidas e assumidas pelos educadores, no interior das instituiçóes escolares.

Finalmente, retomando-se a questāo inicial apresentada neste trabalho, podemos concluir que a escolarizacào tem um papel decisivo no processo de formaça da ciđadania, principalmente para os alunos oriundos dos setores mais pobres da sociedade. Além disso, a açāo escolar poderiaser muitomais eficiente $e$ relevante neste sentido. Isto vai depender da clareza politica dos seto. res sociais e de seu poder de organizaçào para atuar como grupo de pressāo visando à alceraçào dos fátores extrá e intra-escolares res. ponsáveis pelo fracasso escolar. $\mathrm{O}$ mesmo vale para os profissionais que atuam diretamente na ărea educacional, incluindo os psicólogos, que aqui é nossa audiencia majoritária.

Para estes profissionais, apresento uma questào para discussāo: estarào os psicólogos preparados e conscientes para participar desse processo politico que visa transformar a realidade de nossa Escola pública? 